\title{
Justice, Beneficence and the Modern Age
}

\author{
Lenore T. Ealy
}

Published online: 20 July 2011

(C) Springer Science+Business Media, LLC 2011

In an essay that fleetingly traverses the shifting sands of our perceptions of the role of philanthropists in our social and political order, Robin Rogers sets out to differentiate the emerging practices of philanthrocapitalism from philanthropolicymaking. Definitions are required, as we are immediately caught up in something of a multi-syllabic nightmare, typifying our age when social analysis seems to depend more on our ability to coin new words for (supposedly) new phenomena than on our ability to take a trenchant look at the goings-on around us to determine whether there is anything new under the sun.

For neologists Matthew Bishop and Michael Green, philanthrocapitalists are the super-wealthy-or superinfluential (Bill Clinton is a pack leader, though the influence he peddles is largely of political rather than financial derivation) - who "are trying to apply the secrets behind [their] money-making success to their giving." Rogers sums it nicely, "philanthrocapitalists want to bring the virtues of business to charity." Setting aside for now discussion of the feasibility of this quest, we can define the second important term in Rogers' essay, philanthro-policymaking. With this term, Rogers picks up on a core criticism of philanthrocapitalism and differentiates the "agenda setting powers of the new global elite" from the tools they are developing and deploying to obtain better results from their charitable giving. This is an important distinction, and one that points to a perennial tension between justice and charity.

Since the dawn of the industrial age, business, philanthropy and policy have engaged in a strange dance requiring the

\section{T. Ealy $(\bowtie)$}

Thinkitecture, Inc.,

1415 Ironwood Dr W,

Carmel, IN 46033, USA

e-mail: lenoree@thinkitecture.com improvisation of new steps as practices of benevolence shifted from the Old World to the New. The Old World was characterized by systems of religious charity, paternalism rooted in agrarian cultures and courtly patronage. In the New World, urbanization and industrialization heightened perceptions of social problems, and Enlightenment conceptions of equality and fraternity have seemed to demand more democratic forms of sanitary protection and welfare provision.

Increasingly disembedded from a social structure that imposed various duties of beneficence, today's successful entrepreneur often faces new questions about whether and how to share his bounty with the less fortunate. Before his ultimate transformation, Ebenezer Scrooge, that fictional functionary of the early "financial services industry," encapsulated the belief that policy could displace charity. When invited to make a voluntary subscription in support of the poor, Scrooge inquired of the door-to-door fundraisers, "Are there no prisons? ... And the Union workhouses? ... Are they still in operation? ... The Treadmill and the Poor Law are in full vigour then?"

Dickens tells us that Scrooge recoiled at the "ominous word "liberality"' and that he and Marley had been kindred spirits in this regard. Today's super-wealthy, by contrast, seem to find some benefit in exploring their kindred spirit for doing good. For Rogers, the Giving Pledge, the voluntary commitment of a few dozen billionaires to devote a substantial portion of their wealth to charity, is philanthrocapitalism, and fairly benign. Meanwhile, the Good Club, a gathering in which the super-wealthy have met to identify social problems toward which they should combine and thus amplify their charitable efforts, is philanthro-policymaking, and potentially nefarious. We can see how persistently things stay the same despite how much then change when we consider how un-imaginative the Good Club's target setting in fact has been. Rogers tells us that in 2009 the Good Club chose global population growth as a 
focal problem. Are there subtle Malthusian echoes here of Scrooge's cold-hearted response when informed that many of the poor would rather die than go to the poorhouse for relief? Unmoved by any sympathy with the dignity of these proud and apparently too abundant poor, Scrooge retorts, "If they would rather die...they had better do it, and decrease the surplus population." There are deep ironies in the population skepticism of those most experienced in the creation of surplus wealth that suggest that our culture has not yet truly grasped or adapted to the new social conditions of democratic capitalism.

Adam Smith, who was among the first to perceive the wealth-creating capabilities of the "system of natural liberty" that was possible when trade was freed from the shackles of mercantilist policy, was also among the first to perceive a need to explain why such liberty of exchange would not result in the dissolution of human sociality. Thus the same author who observed that it is from the self-interest of the tradesman, not from his benevolence, that we should expect our dinner would also write that "However selfish soever man may be supposed, there are evidently some principles in his nature, which interest him in the fortune of others, and render their happiness necessary to him...."

In The Theory of Moral Sentiments, Smith explored the tension between justice and beneficence that has been a persistent philanthropic concern. It is largely this tension to which Rogers points us in her reflections upon the dangers of philanthro-policymaking. These dangers, she suggests, largely lay in the presumption of the superwealthy to establish social ends outside of the public discourse and political mechanisms that modern democratic nations have established for these purposes. The danger of this presumption, of course, is that the extreme wealth possessed by the philanthrocapitalists actually empowers them to pursue these ends to some effect. Were you (presuming few billionaires are reading these pages) and I to get together and decide to remake the world out of our own sense of good, the danger would be merely quixotic; without hundreds of millions of dollars to foment social change we would potentially do more harm to ourselves and our loved ones than to society at-large.

When looking at the super-wealthy, however, we do find ourselves facing a variant of Locke's important question, "Who Judge?" Should all redistribution of resources be adjudicated through democratic political institutions designed to approximate a public consensus on social ends? This question seems to be answered affirmatively by advocates of stronger charity regulation and policies such as "greenlining," which would mandate more diverse representation in charitable governance as well as more proportional giving to minority communities (at this time largely defined around racial demographics). Even a cursory public choice analysis of collective decision making, however, suggests that further politicization of social justice concerns will fail to achieve the outcomes desired by social egalitarians suspicious of wealth and its potential misuse by the wealthy.

The tension between justice and beneficence is quite real and deserves to be prominent in the public discourse of a free society. This discussion may be greatly enhanced if we reexamine Adam Smith's framing of the tension. Smith states boldly that "beneficence... is less essential to the existence of society than justice." (167) In establishing justice as the necessary foundation of society, Smith is far from commending the modern conception of "social justice." He anchors his discussion of justice on the necessity of remedial justice designed to resolve private injury to persons and property rather than on distributive justice which orders benefits. "The most sacred laws of justice, therefore, those whose violation seems to call loudest for vengeance and punishment, are the laws which guard the life and person of our neighbour; the next are those which guard his property and possessions; and last of all come those which guard what are called his personal rights, or what is due to him from the promise of others" (163).

Justice in this common law framework is for Smith the "main pillar" of society, but beneficence is the "ornament which embellishes" (167) and is "always free, it cannot be extorted by force." (155) Against this clarity of distinction, the modern pursuit of "social justice" inclines to confuse beneficence and justice, to drive into the realm of policy, and call for the enforcement by police powers, a desire for positive welfare equality that may come at the expense of social harmony by encouraging envy and resentment. A system in which justice absorbs beneficence will also diminish or explicitly proscribe the role of private charity and thus will be lost opportunity for the wealthy to exercise and model the virtues of sympathy through philanthropic endeavor. It was Karl Marx, of course, who drove this suspicion of charity and its practitioners to such radical conclusions, and in the end Rogers is tangling with dilemmas at the heart of the contest between Smith's "system of natural liberty" and Marx's critique of "capitalism." Rogers approves of the philanthrocapitalists' voluntary desire to do good, but remains attendant to the fact that combinations of wealth might amplify the potential harms, to individuals, communities, or nations, that could accompany philanthropy that comes with such huge monetary incentives and influence.

So, how exactly should a free society treat the desires of the super-wealthy to do good? Must we minimize the potential that such large-scale gifts will actually generate greater harm (the nature of unreciprocated and unreciprocable gifts is in fact to generate servility)? If so, how do we do so while respecting the freedom of the superwealthy as persons to exercise and experience the virtues of beneficence? 
Rogers' teasing out of philanthro-policymaking from philanthrocapitalism offers us one possible way to engage the discussion. At the turn of the twentieth century a predominant social concern was to limit the power of business combinations that resulted in commercial and manufacturing monopolies and diminished the benefits of competition. At the turn of the twenty-first century do we face the need to contemplate how philanthropic "combinations"- defined as an over-alignment of social ends by the titans of philanthropy - might likewise be detrimental to some perceived public good? Undoubtedly, unleashing a fire hose of philanthropic funds into any established community is bound to have a plethora of unintended and potentially harmful consequences. A danger, on the other hand, in pursuing greater regulation of philanthropy is that we disrupt the very creativity and potential for virtuous deliberation that philanthropy affords. Rigorously disavowing philanthro-policymaking would require, however, that we begin to seriously consider how to disentangle justice and beneficence and develop a more robust social theory of philanthropy than the third-party governance model of Lester Salamon. We must ask whether the vast government funding currently provided to "charitable" organizations to realize ends set by public policy is in fact also a dangerous form of philanthro-policymaking.

Rather than a monistic philanthropy-whether one absorbed in and dictated by state policy or one seeking to align public policy with its own rationale and ends - we should promote a genuine social pluralism in a "marketplace" of beneficence. Lest the term marketplace distract here, I should clarify that I think continuing to explore the proper relationships between the state, commerce, and philanthropy would help us move beyond the overly simplistic and sometimes silly effort to map business practices and metaphors onto our philanthropy. There are certainly many forms of charitable activity that can and should be moved out of the realm of not-for-profit organization and reconstituted as business activity, where the feedback mechanisms of prices and profit/loss signals could help us more effectively utilize resources for the provision of goods and services. Likewise, there should be a robust conversation in the business world about better responsiveness to consumers, especially those with limited power as consumers, and the trade-offs between short-term profit maximization and longer-term considerations of resource stewardship.

Both of these conversations would help us move toward the more positive social deliberation commended by Richard Cornuelle, author of Reclaiming the American Dream and Healing America, who articulated the growing need we have to restore people's confidence in their capacity for identifying and solving problems they perceive around them. In fact, it is the resumption of distributed social responsibility- diminished during the twentieth century by centralizing political trends and the accretion of power in expansive administrative welfare states - that can most help counterbalance the potential harm of the philanthropy of the superwealthy. A people empowered by a confidence that they can engage, as Cornuelle puts it, in "concerted action, national [or international] in scope but outside government" can form a myriad of social enterprises and associations to realize their common hopes and dreams. Thus mobilized, the "wisdom of crowds" will also be more likely to generate more accurate assessments of the benefits or dangers posed by any potential philanthropic Trojan horse offered by the super-wealthy. Empowered to experiment and associate in pursuit of both their personal and shared goals, whether coincident or collaborate, people can help ensure that responsibility and resources flow toward competence and away from incompetence. Reclaiming their capacities and competencies as producers of their communities rather than as clients of welfare agencies (whether those providing subsistence welfare or an expansive menu of middle-class entitlements), people can recover that civility and conviviality and the beneficent virtues that grow upon the foundation of justice in which rule of law not men prevails.

The fact is that the super-wealthy are destined to be highly controversial, dramatic and alluring public figures in any age. Wealth can foster hubris with catastrophic results. There is perhaps less danger to civil society in the wealthy becoming exhibitionist consumers of luxury goods than in their growing desire to "do good." While sumptuous living may breed the social ill of envy, it may also act as a spur to others to be industrious in seeking the potential benefits of entrepreneurship. The desire to do good is surrounded by moral hazards, and yet we remain hesitant to give up our visions of a more humane society. We thus have three basic options in dealing with the super-wealthy: leveling by progressively taxing them, looking on while they do what they will, or assisting them in discharging what we might call the Spiderman dictum, to him who is given great power is also given great responsibility.

"Where the necessary assistance [men have of one another] is reciprocally afforded from love, from gratitude, from friendship, and esteem," wrote Adam Smith, "the society flourishes and is happy." Perhaps the most humane approach is to treat the wealthy among us as persons not as bank accounts. We might thus encourage and support them in their variety of aspirations to do good. Science fiction writer David Brin, in a provocative essay pre-dating the current attention to philanthrocapitalism, urges that the super-wealthy, those capable not of $\$ 1$ million gifts but of $\$ 100$ million gifts, should be encouraged to aspire to the most high risk, high reward projects imaginable. Brin proposes that "these would be projects that ill-suit the typical investment horizons of industry or government, the two dominant capitalizing forces 
of the 20th Century. Because each is constrained by accountability - to constituents or stockholders - governments and corporations must control risk in ways that don't always hamper an individual billionaire." The dangers of encouraging bold philanthropy in a vacuum of accountability must not be ignored of course. Thus we are called back to contemplate at least three fundamental principles on which philanthropy should rest:

1) All people, from the most poor to the most wealthy, must be deemed capable of exercising the virtues of justice (refraining from injuring others) and beneficence (providing others positive assistance). This means that we resort to policy primarily as a barrier to injury and a promoter of the "system of natural liberty" which alone is an incubator of genuine virtue.

2) All people, from the most poor to the most wealthy, must be regarded with dignity as persons capable of developing personal goals, exercising personal responsibility, and engaging in voluntary reciprocal exchanges of benefits in the realms of both commercial trade and charitable activity.

3) Society must be conceived of foremost not as a utopian goal but as a dynamic space in which conditions of limited knowledge are best ameliorated through institutions that are not designed and managed by an elite but rather emerge as the outcomes of voluntary human action and the deliberations among people seeing themselves engaged in a great journey together.
Cornuelle suggests to us that a good society is that which emerges from "millions and millions of small caring acts, repeated day after day, until direct mutual action becomes second nature and to see a problem is to begin to wonder how best to act on it." This is a vision fitting for the New World and the modern age, yet undiminished in its human capacities for the pursuit of virtue despite the transformation of social, economic and political institutions that gave birth to the most expansively wealth-creating and philanthropic nation in history. From this perspective, philanthrocapitalism may better refer not merely to the practices of a handful of super-wealthy but to the broader social dynamics that both reward entrepreneurship and continually expand opportunities to participate in what Deirdre McCloskey commends to us as the bourgeois virtues. Let's invite the super-wealthy into a conversation with us about the potential we all have to be transformed through charity. Perhaps we may then all aspire, with the Scrooge who returned from his "intercourse with the Spirits," to become "as good a friend, as good a master, and as good a man, as the good old city knew, or any other good old city, town or borough, in the good old world."

Lenore T. Ealy is director of the Project for New Philanthropy Studies at DonorsTrust and editor of the journal Conversations on Philanthropy: Emerging Questions on Liberality and Social Thought. 